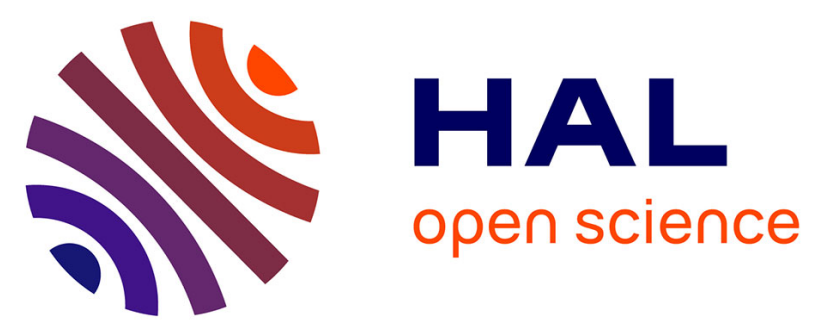

\title{
Is there an association between selective serotonin reuptake inhibitor use and uncomplicated peptic ulcers? A population-based case-control study
}

Michael Dall Dall, Ove B. Schaffalitzky de Muckadell, Annmarie Touborg Lassen, Jesper Hallas

\section{To cite this version:}

Michael Dall Dall, Ove B. Schaffalitzky de Muckadell, Annmarie Touborg Lassen, Jesper Hallas. Is there an association between selective serotonin reuptake inhibitor use and uncomplicated peptic ulcers? A population-based case-control study. Alimentary Pharmacology and Therapeutics, 2010, 32 (11-12), pp.1383. 10.1111/j.1365-2036.2010.04472.x . hal-00580345

\section{HAL Id: hal-00580345 https://hal.science/hal-00580345}

Submitted on 28 Mar 2011

HAL is a multi-disciplinary open access archive for the deposit and dissemination of scientific research documents, whether they are published or not. The documents may come from teaching and research institutions in France or abroad, or from public or private research centers.
L'archive ouverte pluridisciplinaire HAL, est destinée au dépôt et à la diffusion de documents scientifiques de niveau recherche, publiés ou non, émanant des établissements d'enseignement et de recherche français ou étrangers, des laboratoires publics ou privés. 


\begin{tabular}{l}
\hline Alimentary Pharmacology \\
\hline \& Therapeutics \\
\hline
\end{tabular}

\section{Is there an association between selective serotonin reuptake inhibitor use and uncomplicated peptic ulcers? A population-based case-control study}

\begin{tabular}{|c|c|}
\hline Journal: & Alimentary Pharmacology \& Therapeutics \\
\hline Manuscript ID: & APT-0464-2010.R3 \\
\hline Wiley - Manuscript type: & Original Scientific Paper \\
\hline $\begin{array}{l}\text { Date Submitted by the } \\
\text { Author: }\end{array}$ & 06-Sep-2010 \\
\hline Complete List of Authors: & $\begin{array}{l}\text { Dall, Michael Dall; University of Southern Denmark, Institute of } \\
\text { Public Health, Clinical Pharmacology } \\
\text { Schaffalitzky de Muckadell, Ove; Odense University Hospital, } \\
\text { Odense, Department of Medical Gastroenterology } \\
\text { Touborg Lassen, Annmarie; Odense University Hospital, Odense, } \\
\text { Department of Infectious Medicine } \\
\text { Hallas, Jesper; University of Southern Denmark, Odense, Research } \\
\text { Unit of Clinical Pharmacology }\end{array}$ \\
\hline Keywords: & $\begin{array}{l}\text { Peptic ulcer disease < Disease-based, Epidemiology }<\text { Topics, } \\
\text { Endoscopy }<\text { Topics, X keyword = no topic }\end{array}$ \\
\hline
\end{tabular}

\section{SCHOLARONE ${ }^{\text {MM }}$ Manuscripts}




\title{
Is there an association between selective
}

\section{serotonin reuptake inhibitor use and}

\section{uncomplicated peptic ulcers?}

\section{- A population-based case-control study}

\author{
Michael Dall ${ }^{1,2}$, Ove B. Schaffalitzky de Muckadell ${ }^{2}$, Annmarie Touborg \\ Lassen $^{3}$, Jesper Hallas ${ }^{1}$ \\ ${ }^{1}$ Research Unit of Clinical Pharmacology, University of Southern Denmark, \\ Odense; Departments of ${ }^{2}$ Medical Gastroenterology ${ }^{3}$ Infectious Medicine, \\ Odense University Hospital, Odense
}

Short Title: SSRI and risk of uncomplicated peptic ulcers

\section{Correspondence:}

Michael Dall, MD

University of Southern Denmark, Faculty of Health Sciences

Institute of Public Health, Research Unit of Clinical Pharmacology

Winsløwparken 19, 2

DK-5000 Odense C, DENMARK.

Tel: +4565503759

Fax: +4565916089

E-mail: mdall@health.sdu.dk 
Word count: 3407 words

\section{Key words:}

SSRI, selective serotonin reuptake inhibitor; Uncomplicated peptic ulcer, UPU; Upper gastrointestinal bleeding, UGIB; proton pump inhibitor.

\section{Contributors:}

M.D wrote the first protocol draft, validated some cases, participated in the analysis and interpreted data, and wrote the first article draft.

O.B.S.de.M, provided input to the protocol and article and made critical revision of the manuscript for important intellectual content.

A.T.L; provided input to the protocol and article and validated some cases.

J.H provided input to the protocol and article, validated some cases and helped MD with the analysis and interpreted data and made critical revision of the manuscript for important intellectual content.,

All authors have approved the current version. M.D is the guarantor.

\section{Funding:}

The University of Southern Denmark and Funen County provided data free of charge. 


\section{Conflict of interest:}

J.H. has received fees for teaching from AstraZeneca, MSD and the Danish Association of the pharmaceutical Industry, and research grants from Novartis, Pfizer and Nycomed.

O.SdeM. has received fees for teaching from AstraZeneca.

All other authors: none declared. 


\begin{abstract}
Background \& Aims: Persons who use serotonin reuptake inhibitors (SSRIs) seems at increased risk of having serious upper gastrointestinal bleeding. In vitro studies have shown that SSRIs inhibit platelet aggregation. It is unknown if SSRIs has a direct ulcerogenic effect. The aim of this study was to investigate if there is a possible association between use of SSRIs and uncomplicated peptic ulcers (UPU).
\end{abstract}

Methods: A population based case-control study was conducted in the county of Funen, Denmark, using local prescription database and patient register. The 4862 cases all had a first diagnosis of UPU from 1995 to 2009. Controls $(n=19448)$, matched for age and sex, were selected by risk-set sampling.

Results: The adjusted odds ratio (OR) of UPU among current, recent, and past users of SSRIs were 1.50 (95\% CI 1.18-1.90), 1.56 (95\% CI $0.98-$ 2.49), and 1.32 (95\% CI 1.08-1.61). There was no association with tricyclic antidepressants (OR 0.94 (95\% CI $0.65-1.35)$ ). The adjusted OR for the SSRI-UPU association was 0.76 (95\% CI $0.46-1.25)$ among users of proton pump inhibitors. 
Conclusions: Use of SSRI was associated with UPU, possibly by some effect on the healing process. We cannot exclude some effect of residual confounding or bias by frequent physician contact.

Ethics: According to Danish law, neither Ethics Board review nor patient consent is required for register studies. The study was approved by the Danish Data Protection Agency. 


\section{Introduction}

In the last decade, a number of studies have reported an association between use of selective serotonin reuptake inhibitors (SSRIs) and serious upper gastrointestinal bleeding (UGB) ${ }^{1-10}$ but others have not. ${ }^{11-13}$ Some have found an interaction between concurrent use of non-steroidal antiinflammatory drug (NSAID) and SSRI. ${ }^{1,2,4,6,9,12}$ The pharmacological mechanism underlying this adverse effect is thought to depend on the release of serotonin in platelets, which is important for their aggregation process. ${ }^{14}$ Platelets are unable to synthesize serotonin, but can acquire it from the circulation by serotonin transporters. ${ }^{15}$ SSRIs inhibit these transporters and will lower the level of serotonin inside the platelets after a short duration of treatment. ${ }^{16}$

It is unknown if processes other than the anti-thrombocytic effect might be involved in the SSRI-induced UGB, and it is unknown if SSRIs has a direct ulcerogenic effect. We undertook this case-control study to assess a possible association between SSRIs and uncomplicated peptic ulcers (UPU). If the anti-aggregatory effect were the sole mechanism involved, we would not expect an association between SSRIs and UPU. To our knowledge, such an association has not been investigated before. 


\section{Material and methods}

\section{Setting}

The data for this study were retrieved from three different sources, the Funen County Patient Administrative System (FPAS) Odense University Pharmaco-epidemiological Database (OPED) and the Danish Central Person Register (CPR).

Data on patient contacts were retrieved from FPAS. All Funen County (population 470,000) residents have all their discharges from hospitals registered since 1973 and out-patient contacts since 1989. Diagnoses are encoded by the International Classification of Diseases- $8^{\text {th }}$ version (ICD-8) until January 1994, ICD-10 thereafter. ${ }^{17}$ ICD-9 has not been used in Denmark. Since in-patient care is furnished almost exclusively by the national health services, these data sources allow in effect true population based epidemiological studies.

Information on reimbursed drug dispensing in the County of Funen has been recorded in the OPED since 1990 and in the Region of Southern Denmark (population 1.2 million) since the 1st of January 2007.

Each prescription record includes a person identifier, the date of dispensing, the brand, quantity, and form of the drug. The substances and quantities are 
registered according to WHO's anatomical-therapeutic-chemical (ATC) system and defined daily doses (DDD) methodology. ${ }^{18}$ The indication for treatment and the dosing instruction are not recorded. Drugs not reimbursed and therefore not recorded in the database are over-the-counter drugs and some non-reimbursed prescription drugs, mainly oral contraceptives, hypnotics, sedatives and some antibiotics. ${ }^{17}$

We used the Central Person Register ${ }^{19}$ to extract the controls and to ensure that all cases and controls were Funen County residents on their index dates and during the previous 365 days before it.

All these data were linked by using the mutual person identifier, the Central Person Registry (CPR)-code, which is shared with virtually all other health related registries in Denmark, thereby allowing record-linkage studies. ${ }^{19}$ The study was approved by the Danish Data Protection Agency. An ethics committee approval was not required.

\section{Cases and controls}

- Cases $(n=4862)$ were patients who had a diagnosis of UPU, either on an in-patient or an out-patient basis on one of the county's hospitals between January the $1^{\text {st }} 1995$ and January $1^{\text {st }} 2009$. All UPUs were verified by endoscopy. Only the first episode within this time-window was counted. Cases were subdivided into three categories of UPU: 
Uncomplicated duodenal/gastro duodenal ulcers: ICD8: 53291, 53299, 53391, 53399, ICD10: K26.3, K26.7, K26.9, K27.3, K27.7 and K27.9.

- Uncomplicated gastric ulcers: ICD8: 53191, 53193, 53194, 53196, 53198, 53199, ICD10: K25.3, K25.7 and K25.9.

- Others (anastomosis ulcers): ICD8: 53491, 53499, ICD10: K28.3, K28.7 and K28.9.

Cases were given an index date equivalent to the first registered date of an UPU diagnosis. Controls $(n=19448)$ were matched for age- and sex and sampled by use of a risk set sampling technique. In brief, four controls for each case were randomly selected among those within the county who matched the case with respect to gender and exact birth year. The controls were assigned an index date identical to the admission date of the corresponding case. Both cases and controls were required to have been residents of the Funen County (from January $1^{\text {st }} 2007$; the Region of Southern Denmark) for at least one year on the index date. Cases were eligible as control subjects until their first diagnosis of UPU. By this sampling technique, the generated odd ratios will be unbiased estimates of the incidence rate ratios. ${ }^{20}$

\section{Case validation}

We performed a manual review of 500 clinical records randomly chosen among our cases. An UPU was defined as having a mucosal break that was 
$\geq 5 \mathrm{~mm}$ in diameter with appreciable depth. ${ }^{21}$

Not all physicians recorded the size of the ulcera in millimetres but almost everybody described it in manners of e.g. the size of a coin or the severity as "stenosis or narrowing of the bulb". We decided to include such examples as valid UPUs.

$310 / 500(62 \%)$ of UPU diagnoses could be verified, and 163/500 (32.6\%) did not meet our definition of an UPU. $27 / 500$ (5.4\%) could not be accounted for because information was not available in the patient's records or the records were not retrievable.

We tested whether the non-valid cases were different from the valid cases with respect to their SSRI use and found no difference $(p=0.69$, chi-square)

\section{Exposure definition}

All the relevant SSRI doses are available on the Danish market as single tablets. We defined the exposure based on the assumption that the majority of patients would take one tablet per day. This assumption has been validated previously. ${ }^{22}$ To allow for minor non-compliance and for irregular prescription refills, the exposure period were defined as days equivalent to the number of tablets in the dispensed package plus $20 \%$. The exposure period started the day the prescription was redeemed, and the exposure clock was reset with each new prescription. "Recent exposure" was defined 
as the first 90 days after the expiry of an exposure period. The following period was defined as "past exposure". We undertook a sensitivity analysis with the grace period assigned to each prescription of $10 \%, 30 \%$ and $40 \%$ instead of the $20 \%$ used in the primary analysis. Results differed very little from the main analysis (data not shown).

Unless otherwise stated, analyses were based on current exposure, and the reference was person-time never-exposed to SSRI. "SSRI" refers to citalopram (N06AB04), escitalopram (N06AB10), fluoxetine (N06AB03), fluvoxamin (N06AB08), paroxetin (N06AB05) and sertraline (N06AB06).

\section{Data analysis}

The crude and adjusted ORs with 95\% confidence intervals (CI), when relevant, were calculated by use of conditional logistic regression with adjustment for the potential confounders. Age, gender and calendar year were accounted by the study design.

A number of potential confounders were considered;

From FPAS, we retrieved information on the following diagnosis: previous gastric ulcer (ICD8-531; ICD10-K25), duodenal ulcer (ICD8-532; ICD10K26), gastroduodenal ulcers (ICD8-533; ICD10-K27), gastritis and duodenitis (ICD8-535; ICD10-K29), a diagnosis of diabetes (ICD8-250, ICD10 E10-14), hypertension (ICD8- 40, ICD10-I10), congestive heart 
failure (ICD8-427; ICD10-I50), ischemic heart disease or acute myocardial infarction (ICD8 412-414; ICD10 I20-25), cerebral ischemia or stroke (ICD8-431, 433-435; ICD10 I61, I63 and I64 excluding I631 and 641), chronic obstructive pulmonary disease (COPD) (ICD8 490-491; ICD10-J44), any history of alcohol-related disorder (ICD8 303; ICD10-F10, K70.0-K70.9), and psychiatric disorder (ICD8 295-300; ICD10- F20, 30-33).

From OPED we retrieved data on use of the following drugs: NSAIDs (ATC M01A), low dose acetylsalicylic acid (ASA) (ATC B01AC06), oral anticoagulants (ATC B01AA), proton pump inhibitors (PPI) (ATC A02BC), H2 receptor antagonist (ATC A02BA), nitrate vasodilators (ATC C01DA), ever use of antidiabetics (ATC A10), ever use of antihypertensive agents (ATC C03A, C07, C08, C09), ever use of systemic beta-agonists or inhaled anticholinergics (ATC R03C and R03BB), use of disulfiram (ATC N07BB01), statins (ATC C10AA), spironolactone (ATC C03DA01). For all drug exposures except SSRIs, current exposure was defined by the redeeming of a prescription within the past 90 days.

The confounders for the final model were selected by bivariate regression analysis. Potential confounders that changed the OR for SSRI by more than $5 \%$, when added to a model that included only SSRI and case status, were all included. Such confounders were PPI (ATC A02BC), alcohol abuse (ICD8 303; ICD10-F10) and past peptic ulcer (ICD8-533; ICD10-K27). On 
theoretical grounds, we also included low dose ASA (ATC B01AC06), NSAIDS (ATC M01A), corticosteroids (ATC H02AB), Helicobacter eradication ${ }^{23}$, past UGB (ICD8 53190, 53290, 53390 and 53490; ICD10 K25.4, K26.4, K27.4 and K28.4) and cirrhosis (ICD8 571; ICD10 K70.0- K70.9), as these were established risk factors for UPU.

The dose-response relationship was evaluated both in terms of daily dose taken and cumulative dose before the index date. To account for the difference in potency between SSRI, the Prescribed Daily Dose (PDD) was expressed in units of defined daily doses. ${ }^{18}$ Intervals were defined by $\leq 0.5$ $\mathrm{DDD} /$ day, $0.5-1.0 \mathrm{DDD} /$ day and $\geq 1.0 \mathrm{DDD} /$ day.

We defined the index date for the cases as being equivalent to the first registered date of an UPU diagnosis. An UPU could have been present a longer period before the endoscopy was performed. We performed a sensitivity analysis by redefining our index date to occur one and two months before the endoscopy, respectively.

The risk associated with current use of SSRI was expressed in absolute terms by using the NNTH principle ("the number of patients needed to be treated for one additional patient to be harmed"). ${ }^{24}$ The adjusted odds ratios (OR) and the incidence of UPU in the background population unexposed to

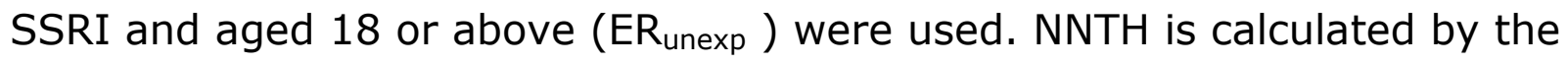
formula; NNTH $=1 /\left(E_{\text {unexp }} \times(O R-1)\right) .{ }^{24}$ We chose to exclude persons 
below 18 years of age from this calculation to avoid inclusion of persons who were unlikely to use SSRIs and unlikely to have UPU and who would dilute the NNTH estimates into unrealistically high values.

All the analyses were performed using Stata release $10.1 .^{25}$

\section{$\underline{\text { Results }}$}

4862 cases were identified, corresponding to an incidence rate of 0.65 per 1000 person years in our background population. 2410 were men (49.6\%), and $1122(23.1 \%)$ were 75 years or older (Table1). Known risk factors such as a past history of ulcer, use of aspirin or NSAIDs were more prevalent among cases than controls. However, other co-morbidity was also more prevalent among cases, such as hypertension, ischemic heart disease and COPD. The extent of current PPI use was 3055 (62.8\%) and $765(3.9 \%)$, among the 4862 cases and 19448 controls respectively. Other characteristics of cases and controls are tabulated in table 1.

There were $838(17.2 \%)$ and $1956(10.1 \%)$, among the 4862 cases and 19448 controls respectively, who had ever taken SSRI. The adjusted OR of UPU among respectively current, recent and past users were 1.50 (95\% CI $1.18-1.90), 1.56$ (95\% CI $0.98-2.49)$ and 1.32 (95\% CI 1.08-1.61) (table 2). The adjusted OR for tricyclic antidepressant (TCA) was 0.94 (95\% CI $0.65-1.35)$. 
Regarding the dose-response association we found the highest adjusted OR for $\geq 1.0$ DDD per day (1.93 (95\% CI 1.05-3.57)). Lower doses were associated with lower risk; the OR was 1.48 (95\% CI 1.13-1.94) and 0.96 (95\% CI $0.43-2.15)$ for doses of $0.5-1.00$ DDD per day and $\leq 0.5$ DDD per day, respectively. For the duration of SSRI use we found the highest adjusted OR for those current users who had started SSRI within the past 30 days, 3.14 (95\% CI 1.20-8.18), while a duration in excess of 180 days was associated with a lower OR, 1.40 (95\% CI 1.07-1.82)(table 2).

The association between SSRI and UPU in subgroups of patients is shown in table 3. We found an OR of 2.16 ( $95 \%$ CI $1.44-3.24$ ) in the group of $\geq 55$ and $<75$ years of age and also an elevated OR (1.71 95\% CI 1.04-2.80) in the group below 55 years of age and no significant association in the group above 75 years of age (OR $1.0795 \%$ CI $0.75-1.54$ ). There was no effect modification by gender. There was no association between SSRI and UPU among users of PPI (OR; $0.7695 \%$ CI $(0.46-1.25))$ The SSRI-UPU association did not differ by ulcer site. The adjusted estimates for gastric, duodenal or other ulcers were 1.50 (95\% CI 1.13-2.00) and 1.43 (95\% CI $0.93-2.20)$, and 1.67 (95\% CI $0.12-21.3)$.

The sensitivity analyses based on redefined index dates showed results, similar to the main analysis (OR; 1.50 (95\% CI $1.18-1.90), 1.53$ (95\% CI 
$1.28-1.83) 1.39(95 \%$ CI $1.17-1.65)$ for index date moved 0,30 and 60 days back in time.

We found 4538 cases aged 18 or above who were unexposed to SSRI, accrued from 5.203.530 person years of follow-up in our background population. The resulting unexposed event rate $\left(E R_{\text {unexp }}\right)$ was 0.87 per 1000 person years. NNTH were calculated to 2300 person years (95\% CI $1300-$ 6400).

\section{Discussion}

In this large case-control study, patients with current use of SSRI had a moderate risk of being diagnosed with UPU. The increasing OR suggests a dose-response effect and a particularly high risk if the SSRI treatment is newly started. We found no association with current use of TCAs. Patients taking PPI appeared to be protected against SSRI-induced UPU.

The current study has several strengths. It is a true population-based study which has full coverage of admission and prescription data. Secondly we have manually validated approximately $10 \%$ of the case material. Thirdly; with the current data we are able to account for a large number of covariates that are potential confounders.

Among the sources of error, we need to consider information bias, selection bias and residual confounding by variables that are not accounted for. 
Unfortunately, not all UPU diagnoses were valid. Our validity of $61 \%$ was on the level of what other researchers have reported ${ }^{23}$. It is unlikely that the validity of a UPU diagnosis would depend on whether the subject was an SSRI user. Thereby, the inclusion of non-valid cases is a non-differential misclassification bias which would tend to dilute the ORs towards unity. ${ }^{26}$ In other words, the true OR without this bias would have been higher. We have performed a crude sensitivity analysis ${ }^{27}$ which showed the OR to be fairly robust over a reasonable range of assumed validity for the diagnoses (data not shown).

It is conceivable that the frequent physician contact entailed in having depression or being treated with SSRIs would lead to endoscopy referral for ulcer-related complaints that would otherwise not come to medical attention. This could generate a spurious SSRI-UPU association. A Norwegian study has showed that if an endoscopy is performed among healthy people, $7.4 \%$ of the males and 4.6 of the women had peptic ulcers. ${ }^{21}$ We attempted to address this "frequent physician contact" bias by analysing the association between anti-hypertensive drugs and UPU, as these drugs were thought to entail frequent physician contact as well. The adjusted ORs for ACEinhibitors, calcium antagonists and thiazides, estimated by the same techniques as for SSRIs, were 1.20 (95\% CI 1.02-1.42), 1.29 (95\% CI 1.07$1.56)$ and 1.16 (95\% CI $0.93-1.45)$, respectively. We thus cannot exclude 
that some of the apparent ulcerogenic effect of SSRIs are attributable to frequent physician contact.

As with any observational study, residual confounding is a possibility. Table 1 shows that cases and controls differ substantially in their prevalence of traits that are risk factors or proxies for risk factors for UPU. As they should in an observational study. However, these risk factors will only bias our estimates to the extent that they are unevenly distributed between users and non-users of SSRIs. In our adjustment, we have included all variables that could be demonstrated as having a small confounding effect, and we have added the known strong risk factors for UPU. We believe it is unlikely that there is strong confounding by variables that have been registered. However, the use of a registry-based approach renders our study vulnerable to potential confounders that are not covered by our databases; alcohol, smoking, and use of ulcerogenic over-the-counter (OTC) drugs. Users of SSRI smoke more than others ${ }^{28}$, but smoking is by itself only a modest risk factor for UPUs. ${ }^{29}$ In addition, our estimates were not altered by the inclusion and exclusion of COPD in our model, i.e., a crude proxy for heavy smoking (OR 1.50 vs 1.49 ). Thus smoking is unlikely to confound our findings substantially. The studies we have been able to locate on alcohol and UPU report no association. ${ }^{30,31}$ Alcohol abuse is a risk factor for bleeding ulcers but the risk is low with moderate to low intake. ${ }^{32}$ We found a SSRI- 
UPU association slightly lower among persons with no markers of alcohol abuse (OR 1.38 CI 95\% (1.08-1.80) (table 3) and we cannot exclude some confounding by this covariate.

High and low dose ASA and some NSAIDs are sold over the counter (OTC), which is not covered by our prescription database. To account for OTC sales, we compared the quantity registered in our database with the available data on total sales. The estimated coverage of our database for high dose ASA, low dose (<= $150 \mathrm{mg}$ ) ASA and NSAIDs was $4 \%, 90.5 \%$ and $84.3 \%$, respectively. The gross sales volume of high-dose ASA was low, compared to low-dose ASA and NSAID; $11.0,65.3$ and 37.9 defined daily doses per 1000 inhabitants per day. ${ }^{33}$ Although our prescription database thus has captured the major part of ulcerogenic drug use, we cannot exclude some residual confounding.

We also need to consider the indication for SSRIs as a source of confounding. To our knowledge, there is no known association between depression per se and UPU. In addition, we found no increased risk among users of tricyclic antidepressants, which have different pharmacological actions but are largely used for the same indications.

Could our results reflect a direct ulcerative effect by SSRI or is it mediated by its well known effect on the platelets? We have not been able to find any 
studies that could indicate a genuine ulcerative effect, but the function of the platelets in the process of healing gastric ulcers has been studied by some groups. ${ }^{34}$ Wallace et al showed in an animal model that the healing process of peptic ulcers was accelerated by vascular endothelial growth factor (VEGF), which is present in the platelets. It has also been shown that plug formation by platelets is inhibited by paroxetine. ${ }^{35}$ This is a part of the same process already described by other groups. ${ }^{14,15,36}$ Wägner et al described that blocking of the serotonin transporters on the surface of the platelets by fluoxetine resulted in lowering of the serotonin concentration inside the platelets. If the platelets already are affected by SSRIs this could induce a possible malfunction which would result in an indirect inhibition of ulcers healing by the lack of VEGF and possibly a delayed plug formation. This would thereby be a feasible mechanism and explanation for the association found between use of SSRIs and UPUs.

In addition we also found the highest adjusted OR for the most recent commencement of SSRI. Platelets are depleted of serotonin ${ }^{36}$ in the first week of treatment but we are not aware of any pharmacological explanation for the initial elevated risk for UPUs unless this could be an indication of a direct ulcerogenic effect. Another possible explanation could be a "depletion of susceptibles" phenomenon also observed with NSAIDs and bleeding ulcers; the highly sensitive subjects develop their bleeding early and the rest 
remain fairly tolerant. ${ }^{37}$ Finally, we found a higher OR for paroxetine than for the other SSRIs. The reason for this is unknown. Paroxetine has a very high affinity among the SSRIs examined in this study and this could be the reason for the magnitude of the OR that we find. ${ }^{38}$ However, it should be mentioned that this was not a pre-specified hypothesis, and it should be corroborated by others before any inferences can be made.

Given the strengths and weaknesses of our setting and the direction and strength of known biases, we believe that the association reported here reflects a genuine biological effect of SSRIs. We cannot exclude some effect of residual confounding or bias by frequent physician contact. Presently, we cannot know which underlying pharmacological action is responsible. Its clinical implications are also uncertain; the high NNTH values indicate that this is not something that should be considered routinely when prescribing SSRIs. In table 3 we found that among users of PPI, there is no association between SSRI and UPU. However, there might be a problem in high risk groups where prophylactic use of PPIs might be relevant. Possibly, PPI may be a relevant measure against SSRI-induced UPU. Further studies are needed in this area. 


\section{References}

1. Dall M, Schaffalitzky de Muckadell OB, Lassen AT, Hansen JM, Hallas J. An Association Between Selective Serotonin Reuptake Inhibitor Use and Serious Upper Gastrointestinal Bleeding. Clin Gastroenterol Hepatol. 2009 Dec;7(12):1314-21.

2. de Abajo FJ, Garcia Rodriguez LA, Montero D. Association between selective serotonin reuptake inhibitors and upper gastrointestinal bleeding: a population-based case-control study. Br Med J 1999; 319: 1106-9.

3. van Walraven C, Mamdani MM, Wells PS et al. Inhibition of serotonin reuptake by antidepressants and upper gastrointestinal bleeding in elderly patients: retrospective cohort study. BMJ 2001; 323: 655-8.

4. Dalton SO, Johansen C, Mellemkjaer $L$, et al. Use of selective serotonin reuptake inhibitors and risk of upper gastrointestinal tract bleeding: a population-based cohort study. Arch Intern Med 2003; 163: 59-64.

5. Tata LJ, Fortun PJ, Hubbard RB et al. Does concurrent prescription of selective serotonin reuptake inhibitors and non-steroidal antiinflammatory drugs substantially increase the risk of upper gastrointestinal bleeding? Aliment Pharmacol Ther. 2005 Aug $1 ; 22(3): 175-81$. 
6. Helin-Salmivaara A, Huttunen T, Grönroos JM et al. Risk of serious upper gastrointestinal events with concurrent use of NSAIDs and SSRIs: a case-control study in the general population. Eur J Clin Pharmacol. 2007 Apr;63(4):403-8.

7. Opatrny L, Delaney JA, Suissa S. Gastro-intestinal haemorrhage risks of selective serotonin receptor antagonist therapy: a new look. $\mathrm{Br} \mathrm{J}$ Clin Pharmacol. 2008 Jul;66(1):76-81.

8. Lewis JD, Strom BL, Localio AR et al. Moderate and high affinity serotonin reuptake inhibitors increase the risk of upper gastrointestinal toxicity. Pharmacoepidemiol Drug Saf. 2008 Apr;17(4):328-35.

9. de Abajo FJ, García-Rodríguez LA. Risk of upper gastrointestinal tract bleeding associated with selective serotonin reuptake inhibitors and venlafaxine therapy: interaction with nonsteroidal anti-inflammatory drugs and effect of acid-suppressing agents. Arch Gen Psychiatry. 2008 Jul;65(7):795-803.

10. Targownik LE, Bolton JM, Metge CJ et al. Selective serotonin reuptake inhibitors are associated with a modest increase in the risk of upper gastrointestinal bleeding. Am J Gastroenterol. 2009 Jun;104(6):1475-82.

11. Dunn NR, Pearce GL, Shakir SA. Association between SSRIs and 
upper gastrointestinal bleeding. SSRIs are no more likely than other drugs to cause such bleeding. BMJ 2000;320:1405-06.

12. Wessinger $S$, Kaplan $M$, Choi $L$ et al. Increased use of selective serotonin reuptake inhibitors in patients admitted with gastrointestinal haemorrhage: a multicentre retrospective analysis. Aliment Pharmacol Ther. 2006 Apr 1;23(7):937-44.

13. Vidal $X$, Ibáñez $L$, Vendrell $L$ et al. Risk of Upper Gastrointestinal Bleeding and the Degree of Serotonin Reuptake Inhibition by Antidepressants : A Case-Control Study. Drug Saf. 2008;31(2):159168.

14. Li N, Wallen NH, Ladjevardi M, Hjemdahl P. Effects of serotonin on platelet activation in whole blood. Blood Coagul Fibrinolysis 1997;8:517-23.

15. Skop BP, Brown TM. Potential vascular and bleeding complications of treatment with selective serotonin reuptake inhibitors. Psychosomatics 1996; 37: 12-16. 
16. Javors MA, Houston JP, Tekell JL, et al. Reduction of platelet serotonin content in depressed patients treated with either paroxetine or desipramine. Int J Neuropsychopharmacol. 2000 Sep;3(3):229-235.

17. Gaist D, Sørensen HT, Hallas J. The Danish Prescription Registries. Dan Med Bull 1997; 44: 445-8.

18. WHO Collaborating Centre for Drug Statistics Methodology. ATC index with DDDs and guidelines for ATC classification and DDD assignment. Oslo: Norwegian Institute of Public Health, 2006.

19. Frank L. Epidemiology. When an entire country is a cohort. Science 2000; 287: 2398-9.

20. Rothman K. Epidemiology: an introduction. Oxford: Oxford University Press, 2002:87.

21. Bernersen B, Johnsen R, Straume B, Burhol PG, Jenssen TG, Stakkevold PA. Towards a true prevalence of peptic ulcer: the Sørreisa gastrointestinal disorder study. Gut. 1990 Sep;31(9):989-92. 
22. Rosholm J-U, Andersen M, Gram LF. Are there differences in the use of seelctive serotonin reuptake inhibitors and tricyclic antidepressants? A prescription database study. Eur J Clin Pharmacol 2001; 56: 923-29.

23. Lassen A, Hallas J, Schaffalitzky de Muckadell OB. Eradication of Helicobacter pylori and use of antisecretory drugs: population based cohort study. BMJ. 2003 Sep 13;327(7415):603.

24. Bjerre LM, LeLorier J. Expressing the magnitude of adverse effects in case-control studies. BMJ 2000;320:503-6.

25. Release 10.1. StataCorp, 4905 Lakeway Drive, College Station, Texas 77845 USA. http://www.stata.com

26. Rothman K. Epidemiology: an introduction. Oxford: Oxford University Press, 2002:100.

27. Rothman K, Episheet, Spreadsheets for the analysis of Epidemiologic Data, June 112008. 
28. Bak S, Tsiropoulos I, Kjærsgaard JO, et al. Selective serotonin reuptake inhibitors and the risk of stroke: A population based casecontrol study. Stroke 2002; 33: 1465-73.

29. Kurata JH, Nogawa AN. Meta-analysis of risk factors for peptic ulcer. Nonsteroidal antiinflammatory drugs, Helicobacter pylori, and smoking. J Clin Gastroenterol. 1997 Jan;24(1):2-17.

30. Adami H-O, Bergström $\mathrm{R}$, Nyren $\mathrm{O}$, et al. Is duodenal ulcer really a psychosomatic disease? A population-based case-control study. Scand J Gastroenterol 1987;22:889-96.

31. Friedman GD, Siegelaub AB, Seltzer CC. Cigarettes, alcohol, coffee and peptic ulcer. N Engl J Med 1974;290:469-73.

32. Kaufman DW, Kelly JP, Wiholm BE, et al. The risk of acute major upper gastrointestinal bleeding among users of aspirin and ibuprofen at various levels of alcohol consumption. Am J Gastroenterol. 1999 Nov;94(11):3189-96.

33. http://www.medstat.dk, December 2009. 
34. Wallace JL, Dicay M, McKnight W, Dudar GK. Platelets accelerate gastric ulcer healing through presentation of vascular endothelial growth factor. Br J Pharmacol. 2006 Jun;148(3):274-8.

35. Hergovich N, Aigner M, Eichler HG, Entlicher J, Drucker C, Jilma B. Paroxetine decreases platelet serotonin storage and platelet function in human beings. Clin Pharmacol Ther. 2000 Oct;68(4):43542.

36. Wägner A, Montero D, Mårtensson B et al. Effects of fluoxetine treatment of platelet $\mathrm{H}$-imipramine binding, $5-\mathrm{HT}$ uptake and $5-\mathrm{HT}$ content in major depressive disorder. Affect Disord. $1990 ; 20(2): 101$ 13.

37. Moride Y, Abenhaim L. Evidence of the depletion of susceptibles effect in non-experimental pharmacoepidemiologic research. J Clin Epidemiol. 1994 Jul;47(7):731-7.

38. de Abajo FJ, Montero D, Rodríguez LA, Madurga M. Antidepressants and risk of upper gastrointestinal bleeding. Basic Clin Pharmacol Toxicol. 2006 Mar;98(3):304-10. 


\section{Table 1}

Characteristics of $\mathbf{4 8 6 2}$ cases of uncomplicated ulcers and their 19448 control subjects.

\begin{tabular}{|c|c|c|c|}
\hline & Cases $(n=4862)$ & $\begin{array}{l}\text { Controls } \\
(n=19448)\end{array}$ & p-values \\
\hline Age, mean (SD) & $60.7( \pm 16.2)$ & $60.7( \pm 16.2)$ & \\
\hline$<55$ & $1772(36.4 \%)$ & $7088(36.4 \%)$ & 1.00000 \\
\hline$\geq 55 \&<74$ & $1968(40.5 \%)$ & $7872(40.5 \%)$ & 1.00000 \\
\hline$\geq 75$ & $1122(23.1 \%)$ & $4488(23.1 \%)$ & 1.00000 \\
\hline Men & $2410(49.6 \%)$ & $9640(49.6 \%)$ & 1.00000 \\
\hline \multicolumn{4}{|l|}{$\begin{array}{l}\text { Current drug use } \\
\text { (ATC code): }\end{array}$} \\
\hline $\begin{array}{l}\text { - Low-dose aspirin } \\
\text { (B01AC06) }\end{array}$ & $461(9.5 \%)$ & $1050(5.4 \%)$ & $<0.0001$ \\
\hline $\begin{array}{l}\text { - Anticoagulants } \\
\text { (B01AA) }\end{array}$ & $109(2.2 \%)$ & $317(1.6 \%)$ & 0.0036 \\
\hline - NSAIDs (M01A) & $838(17.2 \%)$ & $1819(9.4 \%)$ & $<0.0001$ \\
\hline $\begin{array}{l}\text { - Systemic } \\
\text { corticosteroids } \\
\text { (H02AB) }\end{array}$ & $236(4.9 \%)$ & $512(2.6 \%)$ & $<0.0001$ \\
\hline - H2RA (A02BA) & $977(20.1 \%)$ & $332(1.7 \%)$ & $<0.0001$ \\
\hline - PPIs (A02BC) & $3055(62.8 \%)$ & $765(3.9 \%)$ & $<0.0001$ \\
\hline - Statins (C10AA) & $291(6.0 \%)$ & $827(4.3 \%)$ & $<0.0001$ \\
\hline - Nitrates (C01DA) & $242(5.0 \%)$ & $403(2.1 \%)$ & $<0.0001$ \\
\hline - TCA (N06AA) & $100(2.1 \%)$ & $325(1.7 \%)$ & 0.0665 \\
\hline $\begin{array}{l}\text { - Spironolactone } \\
\text { (C03DA01) }\end{array}$ & $112(2.3 \%)$ & $171(0.9 \%)$ & $<0.0001$ \\
\hline \multicolumn{4}{|l|}{ History of: } \\
\hline - Hp eradication & $1276(26.2 \%)$ & $207(1.1 \%)$ & $<0.0001$ \\
\hline $\begin{array}{l}\text { - Chronic } \\
\text { obstructive lung }\end{array}$ & $289(5.9 \%)$ & $659(3.4 \%)$ & $<0.0001$ \\
\hline
\end{tabular}


disease

- Peptic ulcer

$555(11.4 \%)$

$419(2.2 \%)$

$<0.0001$

- UGB

$154(3.2 \%)$

$92(0.5 \%)$

$<0.0001$

- Ischemic heart

$643(13.2 \%)$

1139 (5.9\%)

$<0.0001$

disease

- Hepatic cirrhosis

$61(1.3 \%)$

$71(0.4 \%)$

$<0.0001$

- Diabetes mellitus 309 (6.4\%)

$784(4.0 \%)$

$<0.0001$

- Renal failure

$62(1.3 \%)$

$74(0.4 \%)$

$<0.0001$

- Heart failure

$328(6.7 \%)$

$784(4.0 \%)$

$<0.0001$

- Hypertension

$535(11.0 \%)$

$1191(6.1 \%)$

$<0.0001$

- Stroke

$274(5.6 \%)$

$642(3.3 \%)$

$<0.0001$

- Alcohol related

$329(6.8 \%)$

468 (2.4\%)

$<0.0001$

diagnosis\#

- Alcohol related

$76(1.6 \%)$

$101(0.5 \%)$

$<0.0001$

prescriptions

(disulfiram)

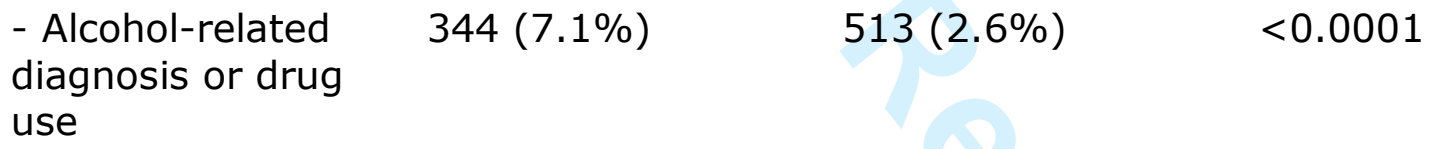

\#: ICD8; 295-300, ICD10; F10, F20, 30-33 and K70.0-K70.9. Unless otherwise indicated, data are shown in numbers. 


\section{Table 2}

Association between exposure to Selective Serotonin Reuptake Inhibitors and Uncomplicated Peptic Ulcers

$\begin{array}{llcc}\text { Cases } & \text { Controls } & \begin{array}{c}\text { Crude Odds Ratio } \\ 95 \% \mathrm{Cl}\end{array} & \begin{array}{c}\text { Adjusted Odds } \\ \text { Ratio } 95 \% \mathrm{Cl}\end{array} \\ \begin{array}{l}\text { Uncomplicated } \\ \text { Peptic Ulcers }\end{array} & \begin{array}{l}\text { Exposed/ } \\ \text { Unexposed }\end{array} & & \\ \text { Exposed/ } & & & \\ \text { Unexposed } & & & \end{array}$

Exposure:

\begin{tabular}{|c|c|c|c|c|}
\hline SSRI, current use & 324 / 4024 & 657 / 17492 & $2.19(1.90-2.54)$ & $1.50(1.18-1.90)$ \\
\hline SSRI, recent use & 82 / 4024 & 158 / 17492 & $2.39(1.80-3.18)$ & $1.56(0.98-2.49)$ \\
\hline SSRI, past use & 432 / 4024 & 1141 / 17492 & $1.74(1.54-1.96)$ & $1.32(1.08-1.61)$ \\
\hline \multicolumn{5}{|l|}{$\begin{array}{l}\text { Antidepressants } \\
\text { substance: }\end{array}$} \\
\hline $\begin{array}{l}\text { Fluoxetine } \\
\text { (N06AB03) }\end{array}$ & $24 / 4024$ & 40 / 17492 & $2.42(1.43-4.10)$ & $1.32(0.58-3.00)$ \\
\hline $\begin{array}{l}\text { Citalopram } \\
\text { (N06AB04) }\end{array}$ & $172 / 4024$ & 365 / 17492 & $2.05(1.69-2.49)$ & $1.38(1.00-1.90)$ \\
\hline Paroxetine & & & & \\
\hline $\begin{array}{l}\text { (N06AB05) } \\
\text { Sertraline }\end{array}$ & 30 / 4024 & 62 / 17492 & $2.54(1.57-4.11)$ & $4.86(2.28-10.4)$ \\
\hline $\begin{array}{l}\text { (N06AB06) } \\
\text { Fluvoxamine }\end{array}$ & 59 / 4024 & 122 / 17492 & $2.23(1.60-3.10)$ & $1.50(0.87-2.58)$ \\
\hline (N06AB08) & $1 / 4024$ & $2 / 17492$ & $1.81(0.16-20)$ & $4.57(0.02-988)$ \\
\hline $\begin{array}{l}\text { Escitalopram } \\
\text { (N06AB10) }\end{array}$ & $38 / 4024$ & $66 / 17492$ & $2.61(1.71-4.00)$ & $1.06(0.52-2.17)$ \\
\hline $\begin{array}{l}\text { Tri-cyclic } \\
\text { antidepressants } \\
\text { (N06AA) }\end{array}$ & $100 / 3970$ & 325 / 17289 & $1.35(1.07-1.71)$ & $0.94(0.65-1.35)$ \\
\hline
\end{tabular}


SSRI dose:

$\begin{array}{lllll}\begin{array}{l}\text { S0-0.5 DDD per } \\ \text { day }\end{array} & 22 / 4024 & 71 / 17492 & 1.36(0.82-2.26) & 0.96(0.43-2.15) \\ \begin{array}{l}\text { 0.5-1.0 DDD per } \\ \text { day }\end{array} & 246 / 4024 & 508 / 17492 & 2.17(1.84-2.55) & 1.48(1.13-1.94) \\ \begin{array}{l}\text { >1.0 DDD per day } \\ \text { SSRI duration: }\end{array} & 56 / 4024 & 78 / 17492 & 3.24(2.24-4.71) & 1.93(1.05-3.57) \\ \text { 0-30 days } & 16 / 4024 & 25 / 17492 & 2.71(1.40-5.25) & 3.14(1.20-8.18) \\ \text { 31-90 days } & 29 / 4024 & 41 / 17492 & 3.10(1.87-5.14) & 1.62(0.69-3.82) \\ \text { 91-180 days } & 20 / 4024 & 37 / 17492 & 2.69(1.51-4.81) & 2.19(0.78-6.16) \\ >180 \text { days } & 259 / 4024 & 554 / 17492 & 2.08(1.77-2.44) & 1.40(1.07-1.82)\end{array}$

Adjusted for; low-dose aspirin, proton pump inhibitors, NSAIDS, alcohol abuse, cerebral ischaemia, stroke, corticosteroids, helicobacter eradication, past peptic ulcer, past upper gastrointestinal bleeding and cirrhosis. Abbreviations: CI; 95\% confidence interval, SSRI; selective serotonin reuptake inhibitors 
9

10 Stratum

21

22

44 No ischemic heart 45 disease 46

47 Heart failure 48

49 No heart failure 50

51 Hypertension or

52 use of

53 antihypertensives 54 \#) 55 56 57 58 59 60

\section{Table 3}

Stratum specific odds ratios for the association between current use of SSRI and uncomplicated peptic ulcers

Current drug use (ATC code)

ASA current use

\section{$44 / 350$}

$280 / 3674$

$225 / 2479$

99 / 1545

$81 / 637$

$243 / 3387$

$58 / 480$

$266 / 3544$

$34 / 250$

$290 / 3774$

$185 / 1394$ controls

exposed/unexposed

$203 / 9007$

454 / 8485

144 / 6616

$215 / 7163$

$298 / 3713$

$95 / 824$

562 / 16668

$81 / 560$

$576 / 16932$

89 / 1545

$568 / 15947$

$91 / 918$

$566 / 16574$

$60 / 628$

$597 / 16864$

$330 / 4404$ $\begin{array}{ll}\text { Crude Odds Ratio } & \text { Adjusted Odds } \\ (95 \% \mathrm{Cl}) & \text { Ratio }(95 \% \mathrm{Cl})\end{array}$

$1.86(1.44-2.42) \quad 1.47(0.96-2.25)$

$2.37(1.99-2.82) \quad 1.48(1.11-1.98)$

$2.86(2.14-3.82) \quad 1.71(1.04-2.80)$

$2.96(2.35-3.73) \quad 2.16(1.44-3.24)$

$1.33(1.03-1.70) \quad 1.07(0.75-1.54)$
$0.99(0.46-2.11) \quad 1.06(0.31-3.61)$

$2.47(2.10-2.90) \quad 1.77(1.35-2.32)$

$0.91(0.59-1.39) \quad 0.76(0.46-1.25)$

$2.24(1.72-2.92) \quad 1.85(1.39-2.47)$

$1.77(0.98-3.18) \quad 0.88(0.35-2.21)$

$2.17(1.83-2.58) \quad 1.68(1.27-2.24)$

$1.24(0.62-2.49) \quad 1,81(0.62-5.25)$

$2.31(1.95-2.72) \quad 1.60(1.22-2.10)$

$0.53(0.16-1.75) \quad 0.16(0.02-1.20)$

$2.26(1.93-2.64) \quad 1.60(1.23-2.07)$

$1.74(1.36-2.24) \quad 1.42(0.96-2.10)$ 
No hypertension or

use of

antihypertensives

$139 / 2630$

$327 / 13088$

$2.33(1.82-2.99) \quad 1.92(1.28-2.88)$

Alcohol abuse or

ever use of

10 disulfiram

12 No alcohol abuse or

13 ever use of

14 disulfiram

Adjusted for; low-dose aspirin, proton pump inhibitors, NSAIDS, alcohol abuse, cerebral ischaemia, stroke,corticosteroids, helicobacter eradication, past peptic ulcer, past upper gastrointestinal bleeding and cirrhosis. Abbreviations: CI; 95\% confidence interval; SSRI; selective serotonin reuptake inhibitors, ATC; Anatomical Therapeutic Chemical, NSAID; non-steroidal anti-inflammatory drugs, ASA; acetylsalicylic acid, PPI; proton pump inhibitors, \#): ACE inhibitors, calcium antagonist, AT2-antagonist, Beta blockers and Thiazids. 